and it must have been difficult at times to make sure that the constants were accurately given. The amplitudes for Gibraltar are ten times too great, but in general the constants appear to be trustworthy.

An immense amount of labour must have been expended in preparing these tables, and all concerned in the production of the manual deserve congratulation upon the efficient manner in which the work has been carried out.

Another activity of the Survey is shown by the two publications dealing with the tides and currents in New York Harbour and in San Francisco Bay. Altogether apart from their importance in navigation, tides and tidal currents enter as important factors into a number of problems connected with harbours and ports. These special publications are not devoted to the discussion of any involved mathematical theory of tides and currents, but are intended to present and discuss the results of observations in such a manner that they will be of interest and practical value to the mariner, the engineer, and the scientific worker. Mr. Marmer's introduction, however, is an admirable statement in simple language of the general characteristics of tides, and this is reprinted in the second publication.

The heights of various planes, such as mean sea level, mean tide level, mean high-water level, storm high-water level, and so on, from year to year are tabulated, explained, and discussed. Engineers must find this information exceedingly useful. Maps give the directions of current flow at intervals of time related to high-water time or to the time of high-water slack.

The importance of tidal currents is becoming increasingly recognised, and the Survey has taken the lead in preparing a separate annual volume of predictions of tidal currents. Hitherto, the current predictions for San Francisco Entrance refer only to the times of slack water for each day of the year, with suitable indications as to whether the current is about to turn from east to west, or vice versa. Beginning with the year I926, however, the predictions will be considerably elaborated. For each day will be tabulated the time of slack water before flood, the time and velocity of each maximum flood, and corresponding times and velocities connected with the ebb. It will be noticed that fifty per cent. more information is given for the currents than for the elevations.

To meet the need for a portable tide gauge suitable for the use of hydrographic parties requiring tidal observations during a period of soundings, an instrument has been designed which appears to have reached almost the lowest practical limit of size. When encased, the instrument is almost a cube of I I inches side, and it is supported on $3 \frac{1}{2}$-inch stock iron pipe which serves as a float-well at the same time. According to Commander Rude the apparatus will function for a week without attention. The gauge appears to be well suited to the purposes for which it is designed.
A. T. Doodson.

\title{
Research in Textiles.
}

THE Fabrics Co-ordinating Research Committee was appointed in I92I, its members being representatives of the fighting services, the National Physical Laboratory, and the research associations for the textile industries. The duties of the Committee are the maintenance of co-ordination between research work on fabrics carried out by Government departments and others, and the direction of new investigations which appear necessary in the national interest and of civilian as well as of naval or military importance. The report recently issued ${ }^{1}$ on the activities of the Committee during the past four years gives a lucid summary of progress in the scientific investigation of several problems of considerable national importance and of very diverse character.

The academic research worker will be interested to learn how frequently, in the solution of such problems, the application of laboratory results is limited by considerations apparently foreign to the subject, a striking illustration being afforded by the search for an antiseptic which will give protection to a fabric from the attacks of micro-organisms and, at the same time, have no deleterious effect upon it. This seemingly simple problem becomes very complex in practice, most antiseptic substances being excluded on account of some objectionable quality or an equally objectionable action on the properties of the fabric or the substances employed in dyeing or finishing this.

The Committee has initiated work on the deterioration of fabrics by the action of light, a problem of great urgency in connexion with aircraft, clothing and tentage, and a summary is given of recent work on the determination of the destructive band of the

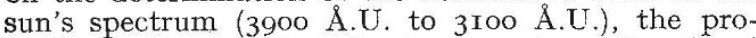
tective action of dyes having an absorption band covering this region, and the mechanism of deterioration. Much further work on the latter subject is required, for the causes are still obscure; but an interesting theory of the action of ozone in this

1 Department of Scientific and Industrial Research. First Report of the Fabrics Co-ordinating Research Committee. Pp. iv+7o. (London: H.M. Stationery Office, I925.) Is. $9 d$. net. connexion is outlined. This takes account of the oxygen adsorbed by the fibres and the possibility of this being ozonised by the direct action of sunlight, and is based upon a calculation by Lindeman that the ozonisation of the adsorbed air may be effected by light of wave-length $3200 \AA$.U.

Future progress depends largely upon the provision of more suitable sources of light for experimental purposes than sunlight or the mercury vapour lamp, and a more delicate means of measuring deterioration than the strength test. It is satisfactory to learn that research is being conducted on both these subjects.

An interesting appendix on the deterioration of fabrics by micro-organisms sketches the organisation of a large-scale attempt to collect systematically the organisms capable of causing the decay of fabrics. Specimens of the latter are being exposed, under the supervision of mycologists, at a number of stations in the British Empire, and arrangements are being made for the examination of the specimens after exposure. Again, the possibility of a more suitable test of deterioration than those now available requires further exploration.

A large section of the report is devoted to a comparison of fabric strength tests carried out on machines of different makes and capacities. From a technical point of view this is probably the most important section, for the results are of direct practical significance. They should, naturally, be read with great interest by all concerned with the mechanical testing of fabrics and the scientific investigation of the principles underlying the methods employed.

As a précis of the results of scientific research the report is highly commendable. A misleading statement has been noticed on p. 30, where it is stated, in a discussion of rate of loading, that, when textiles are broken, a larger percentage of the interlaced fibres are "disentangled and slip past one another without breakage." So far as the writer is aware, there is no evidence supporting this generalisation, which, for example, certainly does not apply to a fine yarn broken on the ballistic tester.
F. Summers. 